\title{
Neuregulin 1 Promotes Excitatory Synapse Development and Function in GABAergic Interneurons
}

\author{
Annie K. Ting, Yongjun Chen, Lei Wen, Dong-Min Yin, Chengyong Shen, Yanmei Tao, Xihui Liu, Wen-Cheng Xiong, \\ and Lin Mei \\ Institute of Molecular Medicine and Genetics and Department of Neurology, Medical College of Georgia, Augusta, Georgia 30912
}

\begin{abstract}
Neuregulin 1 (NRG1) and its receptor ErbB4 are both susceptibility genes of schizophrenia. However, little is known about the underlying mechanisms of their malfunction. Although ErbB4 is enriched in GABAergic interneurons, the role of NRG1 in excitatory synapse formation in these neurons remains poorly understood. We showed that NRG1 increased both the number and size of PSD-95 puncta and the frequency and amplitude of miniature EPSCs (mEPSCs) in GABAergic interneurons, indicating that NRG1 stimulates the formation of new synapses and strengthens existing synapses. In contrast, NRG1 treatment had no effect on either the number or size of excitatory synapses in glutamatergic neurons, suggesting its synaptogenic effect is specific to GABAergic interneurons. Ecto-ErbB4 treatment diminished both the number and size of excitatory synapses, suggesting that endogenous NRG1 may be critical for basal synapse formation. NRG1 could stimulate the stability of PSD-95 in the manner that requires tyrosine kinase activity of ErbB4. Finally, deletion of ErbB4 in parvalbumin-positive interneurons led to reduced frequency and amplitude of mEPSCs, providing in vivo evidence that ErbB4 is important in excitatory synaptogenesis in interneurons. Together, our findings suggested a novel synaptogenic role of NRG1 in excitatory synapse development, possibly via stabilizing PSD-95, and this effect is specific to GABAergic interneurons. In light of the association of the genes of both NRG1 and ErbB4 with schizophrenia and dysfunction of GABAergic system in this disorder, these results provide insight into its potential pathological mechanism.
\end{abstract}

\section{Introduction}

GABAergic interneurons, about $20 \%$ of the neurons in the neocortex, play a critical role in modulating and synchronizing the activity of excitatory neurons (Markram et al., 2004). Dysfunction of the GABAergic system has been implicated in various disorders including epilepsy, bipolar disorder, and schizophrenia (Roberts, 1972; Benes and Berretta, 2001; Lewis and Levitt, 2002). The activity of GABAergic interneurons is controlled by glutamatergic and GABAergic neurons that form, respectively, excitatory and inhibitory synapses on them. Unlike excitatory neurons, synaptogenesis in interneurons has been relatively less studied.

Neuregulin 1 (NRG1) is a family of neurotrophic factors that acts by activating ErbB receptors (Mei and Xiong 2008). Interestingly, ErbB4, the only ErbB protein that is able to bind to NRG1 and has an active kinase domain, is enriched in interneurons (Lai and Lemke, 1991; Yau et al., 2003; Abe et al., 2009; Vullhorst et al., 2009). NRG1 and ErbB4 have been implicated in neural development (Anton et al., 2004; Flames et al., 2004; Lopez-Bendito et al., 2006) and in GABAergic neurotransmission (Woo et al., 2007). Their role in synapse formation has begun to be elucidated.

Received Jan. 10, 2010; revised Aug. 19, 2010; accepted Aug. 31, 2010.

This work was supported in part by grants from the National Institutes of Health (L.M., W.C.X.), the National Alliance for Research on Schizophrenia and Depression (L.M.), and the Muscular Dystrophy Association (L.M.). We thank Dr. Mark Slikowski for NRG1 and Drs. Cary Lai, Silvia Arber, and Yuchio Yanagawa for valuable reagents or mice. The authors declare no competing financial interests.

Correspondence should be addressed to Lin Mei, Institute of Molecular Medicine and Genetics, Medical College of Georgia, Augusta, GA 30912. E-mail: Imei@mcg.edu.

DOI:10.1523/JNEUROSCI.2538-10.2011

Copyright $\odot 2011$ the authors $\quad 0270-6474 / 11 / 310015-11 \$ 15.00 / 0$
Changes in ErbB4 levels or activity altered dendritic spine size, synaptic AMPA receptors, and NMDA currents in neonatal hippocampal slices (Li et al., 2007), suggesting a promoting role of neuregulin in excitatory synapse maturation in glutamatergic neurons. They also altered presynaptic differentiation of both excitatory and inhibitory synapses in hippocampal neurons (Krivosheya et al., 2008). In these studies, however, NRG1 signaling was altered by increasing or suppressing ErbB4 expression, leaving unaddressed a critical question whether NRG1 in fact regulates synapse formation. Although ErbB4 is known to be expressed at higher levels in GABAergic interneurons (Yau et al., 2003; Abe et al., 2009; Vullhorst et al., 2009) and to interact and colocalize with PSD-95 at excitatory synapses in hippocampal interneurons (Huang et al., 2000), the role of NRG1 in postsynaptic differentiation in these neurons remains unclear.

We investigated the role of NRG1 in synaptogenesis in interneurons. First, we studied the effect of NRG1 on synapse formation in both GABAergic interneurons and glutamatergic neurons. Results indicated that the trophic factor promotes assembly of excitatory synapses specifically in GABAergic interneurons. Molecular mechanisms by which NRG1 regulates synapse formation were investigated. We found that NRG1 regulates the stability of PSD-95 in GABAergic neurons in a manner that requires tyrosine kinase activity of ErbB4. These studies identify a previously unrecognized, specific function of NRG1 in promoting excitatory synapse formation in GABAergic interneurons, possibly by stabilizing PSD-95. In consistent with this, ablation of ErbB4 in parvalbumin (PV)-positive interneurons led to reduction in frequency and amplitudes of miniature EPSCs 
(mEPSCs) in mutant mice. In light of the notion that NRG1 and ErbB4 are susceptibility genes of schizophrenia (Stefansson et al., 2002; Yang et al., 2003; Law et al., 2006, 2007), our data contribute to a better understanding of abnormal NRG1 signaling in this devastating disorder.

\section{Materials and Methods}

Reagents and animals. Primary antibodies for immunostaining and dilutions were as follows: mouse PSD-95 (1:250; catalog \#MA1-046; Affinity Bioreagents), rabbit PSD-95 (1:300; catalog \#51-6900; Invitrogen), gephyrin (1:750; catalog \#147011; Synaptic Systems), GABA (1: 3000; catalog \#A 2052; Sigma), PV (1:1000; catalog \#PV235; Swant), and CaMKII (1:300; catalog \#05-532; Millipore). Secondary antibodies for immunostaining and dilutions were as follows: Alexa Fluor 488 anti-mouse (1:500; catalog \#A11029; Invitrogen), Alexa Fluor 594 anti-rabbit (1:500; catalog \#A11012; Invitrogen), and streptavidin-Alexa Fluor 633 conjugate (1:500; catalog \#S21375; Invitrogen). Antibody for Western blot analysis and dilutions were as follows: mouse PSD-95 (1:1000; catalog \#MA1-046; Affinity Bioreagents), gephyrin (1:2000; catalog \#147011; Synaptic Systems), and synapsin (1:2000, catalog \#SC20780; Santa Cruz Biotechnology). NRG1 and ecto-ErbB4 were described previously (Huang et al., 2000; Woo et al., 2007). $\alpha$-Cyano-(3,5di-t-butyl-4-hydroxy)thiocinnamide (AG879) was from Calbiochem, bicuculline was from Tocris Bioscience, biocytin was from Invitrogen, and other chemicals were from Sigma. Myc-PSD-95 was a gift from Dr. Morgan Sheng (Massachusetts Institute of Technology, Cambridge, MA) (Morabito et al., 2004). ErbB4 (JMa/CYT-2) wild-type and kinasedead mutant (K751M) were described previously (Yang et al., 2005). ErbB4 $4^{\text {loxP/loxP }}$ mice were from Dr. Cary Lai (Indiana University, Bloomington, IN) (Garcia-Rivello et al., 2005); PV-Cre mice were from Dr. Silva Arber (University of Basel, Basel, Switzerland) (Arber et al., 2000; Hippenmeyer et al., 2005), and GAD67-GFP ${ }^{+/-}$mice were from Dr. Yuchio Yanagawa (National Defense Medical College Hospital, Saitama, Japan) (Tamamaki et al., 2003). All mice were housed in a room with a $12 \mathrm{~h}$ light/dark cycle with access to food and water ad libitum. Experiments with animals were approved by Institutional Animal Care and Use Committee of the Medical College of Georgia.

Neuron culture. Dissociated neurons were prepared from embryonic day 18 (E18) Sprague Dawley rat or GAD67-GFP ${ }^{+/-}$mouse embryos and cultured in the neurobasal medium (catalog \#21103-049; Invitrogen) supplemented with $1 \times$ B27 (catalog \#17504-044; Invitrogen), $600 \mu \mathrm{M}$ L-glutamine (catalog \#25005-CI; Cellgro), and $1 \times$ penicillin-streptomycin (catalog \#30-003-CI; Cellgro). For low-density culture, $2.5 \times 10^{4}$ cells were seeded on a glass coverslip (1.8 cm in diameter; catalog \#12-545-84; Fisher Scientific) coated for $12 \mathrm{~h}$ with $1 \mu \mathrm{g} / \mathrm{ml}$ poly-L-lysine (catalog \#P2636; Sigma). Twice a week, half of the medium was replaced by freshly prepared medium. For highdensity culture, $2 \times 10^{6}$ cells were seeded in a $60 \mathrm{~mm}$ well plate or $35 \mathrm{~mm}$ the respective bottom image.

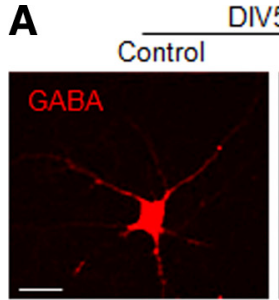

NRG1

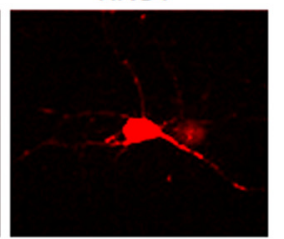

B $\quad \frac{\mathrm{DIV} 12+2}{\mathrm{NRG} 1}$
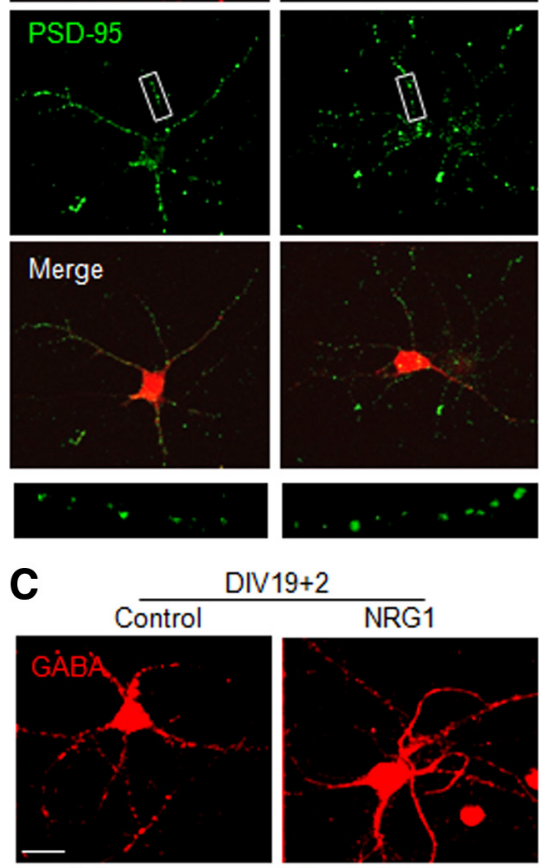

NRG1
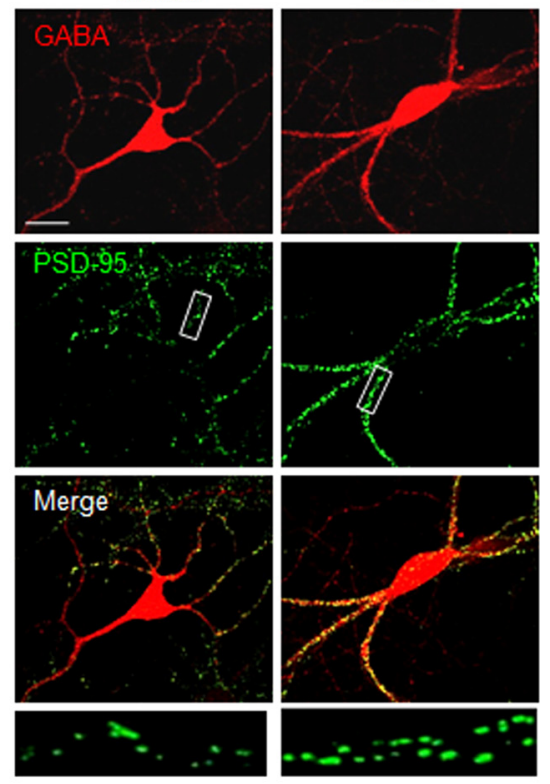

D

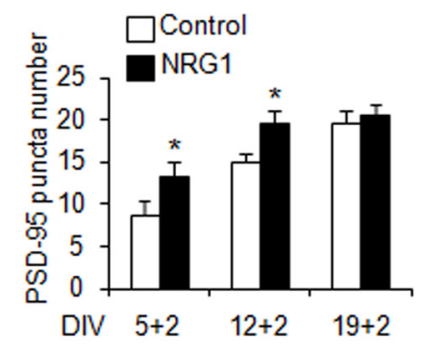

E

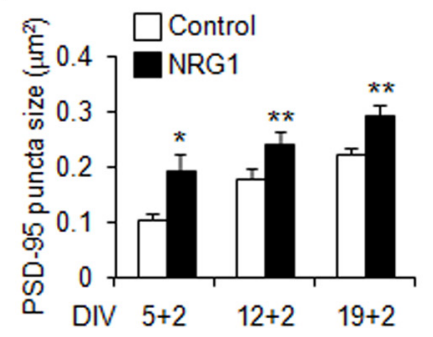

Figure 1. NRG1 facilitates excitatory synapse development in cortical GABAergic interneurons. NRG1 at $5 \mathrm{~nm}$ was applied to low-density DIV5, DIV12, and DIV19 dissociated cortical neurons for $2 \mathrm{~d}$. GABA and PSD-95 were stained to represent GABAergic interneurons and excitatory synapses, respectively. $A-C$, The immunoreactivities of GABA and PSD-95 without or with NRG1 treatment at different developmental. A segment $(30 \mu \mathrm{m})$ of primary or secondary dendrites was subjected for the analysis of PSD-95 puncta number and size. $\boldsymbol{D}, \boldsymbol{E}$, Average PSD-95 puncta number (D) and size (E). Data shown are the mean \pm SEM of four individual experiments. ${ }^{*} p<0.05 ;{ }^{* *} p<0.01$ (DIV5 $+2, n=43$ and 46 for control and treated group; DIV12 $+2, n=46$ and 54 for control and treated group; DIV19 $+2, n=78$ and 73 for control and treated group). For DIV5 +2 , DIV12 +2 , and DIV19 +2 neurons, respectively, puncta numbers are $8.72 \pm 1.73,14.9 \pm 1.05$, and $19.7 \pm 1.37$ in the absence of NRG1 and $13.4 \pm 1.69$, $19.6 \pm 1.54$, and $20.7 \pm 1.20$ in the presence of NRG1; sizes are $10.6 \pm 1.12,17.93 \pm 1.73$, and $22.2 \pm 1.12$ in the absence of NRG1 and 19.2 $\pm 3.03,24.31 \pm 1.95$, and $29.5 \pm 1.65$ in its presence. Scale bar: (in C) $A-C, 30 \mu \mathrm{m}$; boxed area was enlarged in

dish coated with $1 \mu \mathrm{g} / \mathrm{ml}$ poly-L-lysine for $12 \mathrm{~h}$. Half volume of medium was replaced every other day with freshly prepared medium.

Immunostaining in dissociated neurons. Dissociated neurons were fixed with $4 \%$ ice-cold paraformaldehyde for $5 \mathrm{~min}$ at room temperature and washed twice ( 5 min each) with $1 \times$ PBS. Neurons were then permeabilized by $1 \times$ PBS with $0.3 \%$ Triton $X-100$ and $3 \%$ goat serum for $5 \mathrm{~min}$ at room temperature and incubated with primary antibodies in $1 \times$ PBS 
A
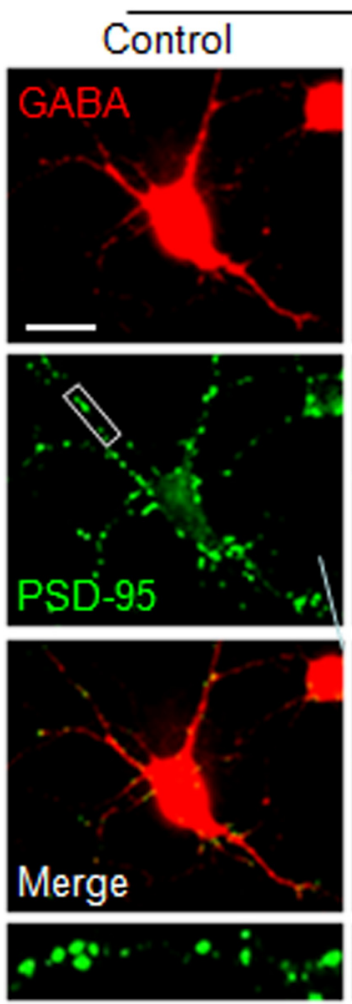

DIV13+1
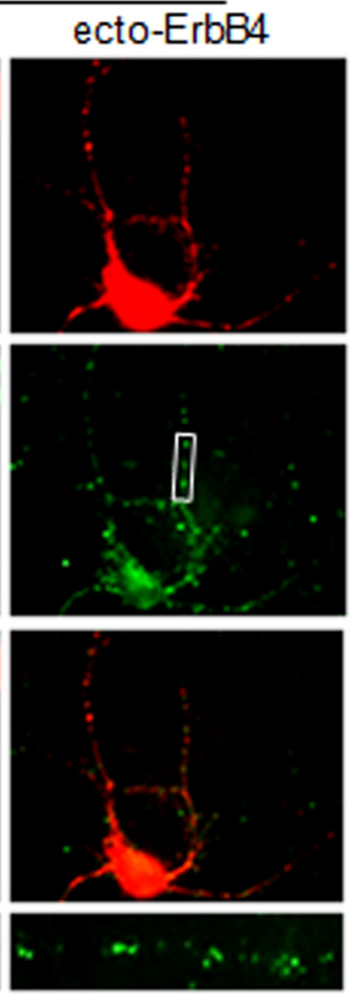

B

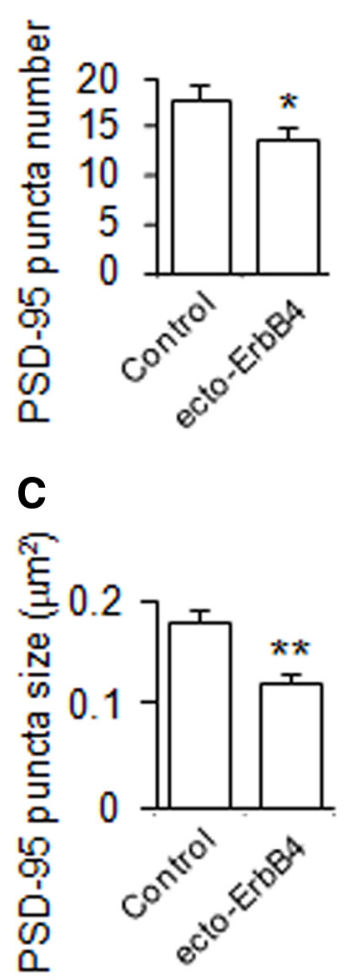

Figure 2. Ecto-ErbB4 blocks the effect of endogenous NRG1 in excitatory synapse development. Ecto-ErbB4 at $0.5 \mu \mathrm{g} / \mathrm{ml}$ was applied to the low-density DIV13 dissociated cortical neurons for $1 \mathrm{~d}$, and the neurons were subjected to immunocytochemistry. GABA and PSD-95 were stained to represent GABAergic interneurons and excitatory synapses, respectively. $\boldsymbol{A}$, Immunoreactivities of GABA and PSD-95. Scale bar, $30 \mu \mathrm{m}$; boxed area was enlarged in the respective bottom image. B, C, PSD-95 puncta, scored as in Figure 1. Data shown are mean \pm SEM of three individual experiments. ${ }^{*} p<0.05$; ${ }^{* *} p<0.01 . n=38$ and 41 for control and treated groups, respectively. Puncta numbers are $17.8 \pm 1.73$ and $13.6 \pm 1.39$ and sizes are $18.0 \pm 1.27$ and $11.2 \pm 0.84$ in the absence and presence of ecto-ErbB4, respectively.

with $0.3 \%$ Triton $\mathrm{X}-100$ and $3 \%$ goat serum for $2 \mathrm{~d}$ at $4^{\circ} \mathrm{C}$. Neurons were rinsed three times with $1 \times \mathrm{PBS}, 5 \mathrm{~min}$ each, and incubated with secondary antibodies in $1 \times$ PBS with $0.3 \%$ Triton X-100 and $3 \%$ goat serum for $75 \mathrm{~min}$ at room temperature. After washing three times with $1 \times$ PBS, 5 min each, neurons were covered with Vectashield mounting medium (H-1000; Vector Laboratories). Images were obtained by confocal scanning microscopy (Zeiss LSM 10 meta). For a given sample, 10-15 images, taken at $0.5 \mu \mathrm{m}$ intervals, were collapsed to generate a projected image. PSD-95 puncta number and size were measured by ImageJ (NIH).

Quantification analysis. All pictures were taken at equal exposure for control and experimental groups. For each primary and secondary dendrite, puncta within a $30 \mu \mathrm{m}$ segment (indicated by a frame) of initiation were counted. The number of dendrites of a typical interneuron is four to six, and $\sim 10$ for a glutamatergic neuron. To avoid bias in data collection, a randomly selected primary dendrite of a particular neuron was designated as number 1 . We counted puncta in all odd-number dendrites. Images were scaled to 16 bits and processed at a constant threshold level by ImageJ. Only puncta with pixel values three times greater than background (nearby dendritic shaft pixel values) were selected for analysis.

Transfection. Human embryonic kidney 293 (HEK293) cells were transfected by electroporation with Nucleofector II from Amaxa Biosystems. Eighty microliters of solution I (363 mM ATP-disodium salt and $590 \mathrm{~mm} \mathrm{MgCl}_{2}-6 \mathrm{H}_{2} \mathrm{O}$ ) were freshly mixed with $4 \mathrm{ml}$ of solution II (147 $\mathrm{mm} \mathrm{KH}_{2} \mathrm{PO} 4,24 \mathrm{~mm} \mathrm{NaHCO}_{3}$, and $34 \mathrm{~mm}$ glucose, $\mathrm{pH} 7.4$ ) as the transfection mix. After trypsinization, $4.5 \times 10^{6} \mathrm{HEK} 293$ cells were centrifuged and resuspended in $100 \mu \mathrm{l}$ of the transfection mix containing $5 \mu \mathrm{g}$ of DNA. The mixture was subsequently transferred to an electroporation cuvette (FE 102; Fisher Scientific), and electroporation was performed following the manufacturer's instruction.
Western blot analysis. Samples were resolved on $8 \%$ SDS-polyacrylamide gels (Mini-PROTE$\mathrm{AN}$; Bio-Rad) and transferred onto nitrocellulose membranes (Whatman). After blocking with 5\% skim milk (catalog \#232100; BD Biosciences) in TBS-Tween 20 (TBS-T) buffer for $45 \mathrm{~min}$ at room temperature, membranes were incubated with a primary antibody in TBS-T buffer overnight at $4^{\circ} \mathrm{C}$. Membranes were washed three times for $10 \mathrm{~min}$ each with TBS-T buffer before application of HRP-coupled secondary antibody (catalog \#31460; Thermo Scientific) overnight at $4^{\circ} \mathrm{C}$. Membranes were then washed three times for 10 min each with TBS-T buffer before application of chemiluminescent HRP antibody detection reagent (E2400; Denville Scientific). The blots were exposed to autoradiography films (E3012; Denville Scientific), and gel band density was quantified.

Electrophysiological recordings. E18 mouse cortical neurons were cultured in vitro for $12-15 \mathrm{~d}$. Neurons were recorded in whole-cell configuration at room temperature. The intracellular recording solution contained (in $\mathrm{mm}$ ) 140 K-gluconate, $2 \mathrm{MgCl}_{2}, 1 \mathrm{CaCl}_{2}, 10 \mathrm{HEPES}, 10$ EGTA, $2 \mathrm{MgCl}_{2}, 2 \mathrm{Mg}$-ATP, and $0.2 \mathrm{Na}-\mathrm{GTP}, \mathrm{pH}$ 7.3 (300 mOsm with sucrose), whereas the extracellular recording solution consisted of (in $\mathrm{mm}$ ) $150 \mathrm{NaCl}, 5.0 \mathrm{KCl}, 2.5 \mathrm{CaCl}_{2}, 1 \mathrm{MgCl}_{2}, 10$ HEPES, 10 glucose, 0.001 tetrodotoxin (TTX), 0.001 strychnine, and 0.02 bicuculline, $\mathrm{pH} 7.3$ (330 mOsm). Cortical neurons were visualized by an infrared-differential interference contrast (DIC) microscope with a $40 \times$ water-immersion lens (BX51WI; Olympus) and an infraredsensitive CCD camera. Interneurons were identified based on green fluorescent protein (GFP) labeling and morphology (the presence of two to six thick curved dendrites with fewer branches). Glutamatergic neurons were recognized by apical dendrites and triangular somata.

Prefrontal cortex (PFC) slices were prepared from P52-P76 PVCre;ErbB4 ${ }^{-/-}$;GAD67GFP ${ }^{+/-}$and PV-Cre;ErbB4 ${ }^{+/+}$;GAD67GFP ${ }^{+/-}$littermates as described previously (Woo et al., 2007). Briefly, coronal PFC slices $(0.40 \mathrm{~mm})$ were prepared with a Vibroslice (Leica VT 1000S) in an ice-cold solution containing the following (in $\mathrm{mM}$ ): $64 \mathrm{NaCl}, 2.5 \mathrm{KCl}, 1.25$ $\mathrm{NaH}_{2} \mathrm{PO}_{4}, 10 \mathrm{MgSO}_{4}, 0.5 \mathrm{CaCl}_{2}, 26 \mathrm{NaHCO}_{3}, 10$ glucose, and 120 sucrose. Slices were recovered for at least $2 \mathrm{~h}\left(1 \mathrm{~h}\right.$ at $34^{\circ} \mathrm{C}$ followed by $1 \mathrm{~h}$ at $\left.22^{\circ} \mathrm{C}\right)$ in artificial CSF (ACSF) until transfer to a recording chamber perfused with ACSF $(2 \mathrm{ml} / \mathrm{min})$ at $34^{\circ} \mathrm{C}$. ACSF containing (in mM) $126 \mathrm{NaCl}, 2.5$ $\mathrm{KCl}, 1.25 \mathrm{NaH}_{2} \mathrm{PO}_{4}, 2 \mathrm{MgSO}_{4}, 2 \mathrm{CaCl}_{2}, 26 \mathrm{NaHCO}_{3}$, and 10 glucose was saturated with $95 \% \mathrm{O}_{2} / 5 \% \mathrm{CO}_{2}$. Whole-cell patch-clamp recordings were performed using an Axon Multiclamp 700B amplifier (Molecular Devices) and digitized by the pClamp 9.2 software (Molecular Devices). Patch electrodes (3-5 M $\Omega$ ) were filled with an internal solution containing the following (in $\mathrm{mm}$ ): $120 \mathrm{~K}$-gluconate, $20 \mathrm{KCl}$, 10 HEPES, 0.1 EGTA, $2 \mathrm{MgCl}_{2}$, 10 sodium phosphocreatine, 0.2 leupeptin, $4 \mathrm{Mg}$-ATP, and $0.3 \mathrm{Na}-\mathrm{GTP}$, pH 7.3 (280 mOsm with sucrose). Biocytin $(0.2 \%)$ was added to the pipette solution for later morphological identification of recorded neurons. PFC layers II-V neurons were visualized by an infrared-DIC microscope with a $40 \times$ waterimmersion lens (Axioskop2 Fsplus; Carl Zeiss) and an infrared-sensitive CCD camera. To characterize membrane properties and firing properties of interneurons, hyperpolarizing and depolarizing current steps were applied for $200 \mathrm{~ms}$ at $0.5 \mathrm{~Hz}$ in current-clamp configuration. Input resistance $\left(R_{\text {in }}\right)$ was measured from the slope of a linear regression fit to the voltage-current relationship in a hyperpolarizing range.

mEPSCs were recorded at a holding potential of $-65 \mathrm{mV}$. TTX $(1 \mu \mathrm{M})$ and bicuculline $(20 \mu \mathrm{M})$ were added to the perfusion solution to block 
$\mathrm{Na}^{+}$currents and $\mathrm{GABA}_{\mathrm{A}}$-receptor-mediated inhibitory postsynaptic currents, respectively. Data were filtered at $2 \mathrm{kHz}$ and sampled at 10 $\mathrm{kHz}$. Neurons with a resting potential of at least $-60 \mathrm{mV}$ and resistance that fluctuated within $15 \%$ of initial values $(<20 \mathrm{M} \Omega)$ were analyzed. Mini events were analyzed with MiniAnalysis software (Synaptosoft). Peak events were detected automatically using an amplitude threshold of twofold the average root mean square noise. Approximately 100-300 events in each cell were included in the analysis. The amplitude histograms were binned at $1 \mathrm{pA}$.

Immunostaining in slices. To identify the PV immunoreactivity of recorded enhanced GFPpositive neurons, biocytin $(0.2 \%)$ was included in the pipette solution. After recordings, slices containing biocytin-filled cells were fixed with $4 \%$ paraformaldehyde and $4 \%$ sucrose in $0.1 \mathrm{M}$ PBS for at least $24 \mathrm{~h}$ at $4^{\circ} \mathrm{C}$. After incubation for $24-48 \mathrm{~h}$ at $4^{\circ} \mathrm{C}$ in blocking solution $(10 \%$ goat serum, $2 \%$ bovine serum albumin, $0.4 \%$ Triton X-100 in $0.1 \mathrm{~m}$ PBS), slices were incubated with anti-parvalbumin antibody (1:1000), 1\% goat serum, and $0.2 \%$ Triton $\mathrm{X}-100$ in $0.1 \mathrm{M}$ PBS at $4^{\circ} \mathrm{C}$ for $36-48 \mathrm{~h}$, and then with streptavidin-Alexa Fluor 633 conjugate (1:500) and Alexa 594-conjugated goat anti-mouse $\operatorname{IgG}(1: 400)$ for $24 \mathrm{~h}$ at $4^{\circ} \mathrm{C}$. Fluorescent images were captured by an LSM 510 confocal laserscanning microscope (Carl Zeiss).

Statistic analysis. Data are presented as mean \pm SEM and were analyzed by two-tailed Student's $t$ test and one-way ANOVA followed by Dunnett's test and the Kolmogorov-Smirnov test (for cumulative frequencies). Changes were considered significant if the $p$ value was $<0.05$. Unless otherwise indicated, in figures, ${ }^{\star} p<0.05,{ }^{* *} p<0.01$, and ${ }^{* * *} p<0.001$.

\section{Results}

NRG1 facilitates the development of excitatory synapses in GABAergic interneurons but not in glutamatergic neurons

Low-density E18 cortical neurons were cultured in vitro until the indicated days [day in vitro 5 (DIV5), DIV12, and DIV19] and subjected to $2 \mathrm{~d}$ NRG1 stimulation. Interneurons were identified by staining with antibody against GABA, which has been used extensively to label inhibitory neurons (Letinic et al., 2002; Heinke et al., 2004). Excitatory synapses were identified by staining of PSD-95, a well-established marker (ElHusseini et al., 2000; Cohen-Cory, 2002; Levinson and El-Husseini, 2005; McAllister, 2007; Keith and El-Husseini, 2008). Because GABA staining of distal dendrites was weak, to avoid possible contamination by dendrites of glutamatergic neurons, only PSD-95 puncta in proximal dendrites were quantified. As shown in Figure $1 A-D$, the number of PSD-95 puncta increased from DIV 5 to DIV19 in GABAergic interneurons in the absence of NRG1. Intriguingly, treatment of NRG1 at $5 \mathrm{nM}$ for $2 \mathrm{~d}$ increased the number of PSD-95 puncta in DIV5 and DIV12 GABAergic interneurons (by $53.8 \pm$ $11.2 \%$ and $31.6 \pm 7.2 \%$ for DIV $5+2$ and DIV $12+2$, respectively), suggesting that NRG1 may stimulate formation of new excitatory synapses in GABAergic interneurons. PSD-95 is thought to promote maturation of excitatory synapses, which correlates with the size of puncta (El-Husseini et al., 2000; Keith and El-Husseini, 2008).
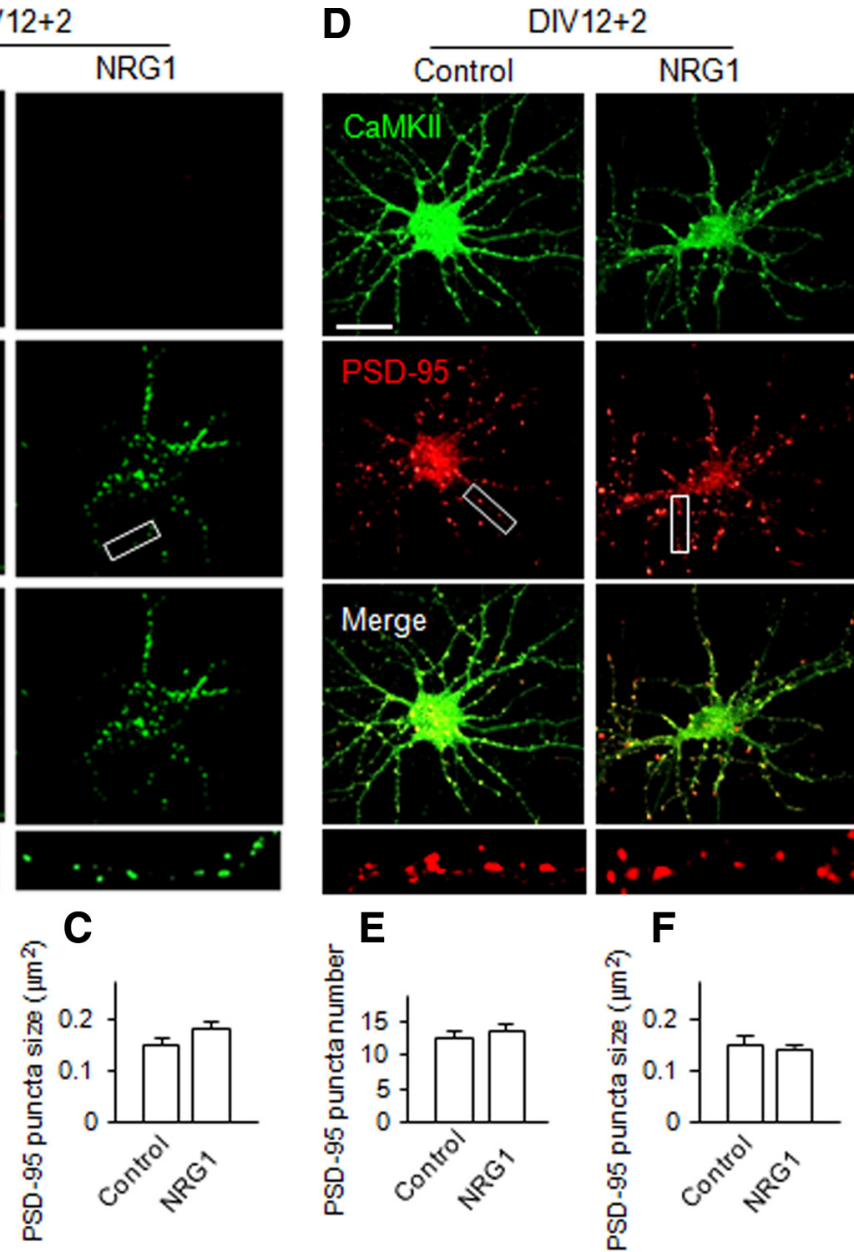

Figure 3. NRG1 has no significant effect on excitatory synapse development in cortical glutamatergic neurons. NRG1 (5 nM) was individual experiments. For GABA-negative neurons ( $n=59$ and 65 for control and treated groups, respectively), puncta numbers 13.1 \pm 0.73 and $11.6 \pm 0.67$ and sizes are $15.8 \pm 1.46$ and $17.1 \pm 2.31$ in the absence and presence of NRG1, respectively. For CaMKII-positive neurons ( $n=74$ and 72 for control and treated groups, respectively), puncta numbers are $11.8 \pm 0.58$ and $12.1 \pm 0.61$ and sizes are $15.3 \pm 0.75$ and $15.3 \pm 0.88$ in the absence and presence of NRG1, respectively.

Therefore, we studied the effect of NRG1 on puncta size. As shown in Figure $1 E$, NRG1 at $5 \mathrm{~nm}$ was able to enhance the size of PSD-95 puncta in GABAergic interneurons at different DIV stages (by $81.8 \pm 18.0 \%, 35.6 \pm 10.2 \%$, and $32.9 \pm 6.8 \%$ for DIV $5+2$, DIV 12 +2 , and DIV19 +2 , respectively). These results indicate that NRG1 could facilitate the formation and maturation of excitatory synapses in GABAergic interneurons. Note that NRG1 treatment of DIV19 interneurons (DIV19 + 2) had no inductive effect on the number of PSD-95 puncta, suggesting that NRG1 promotion of synapse formation depends on the age of developing neurons.

To determine whether excitatory synapse formation in GABAergic interneurons requires endogenous NRG1, DIV13 cortical neurons were treated with ecto-ErbB4. This recombinant protein contains the entire extracellular domain of ErbB4 and has been shown previously to bind to NRG1, and thus prevents NRG1 from activating ErbB kinases (Woo et al., 2007). DIV13 cortical neurons were treated for $1 \mathrm{~d}$ with ecto-ErbB4 at $0.5 \mu \mathrm{g} /$ $\mathrm{ml}$, a concentration that reduces basal activation of ErbB4 in brain slices (Woo et al., 2007). Vehicle treatment had no effect on PSD-95 puncta number or size (supplemental Fig. S1, available at 
A
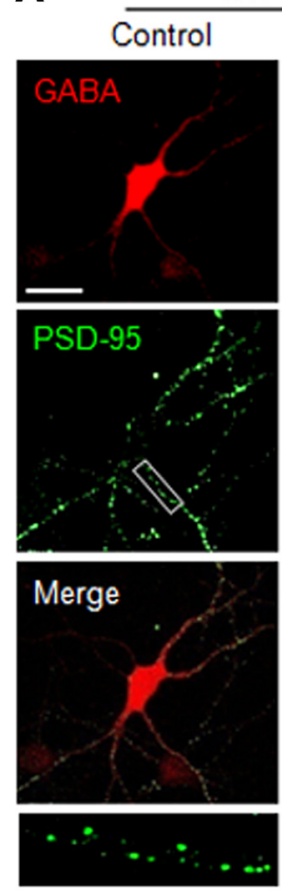

B

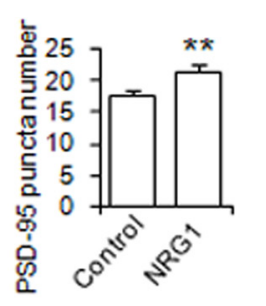

DIV12+2 NRG1
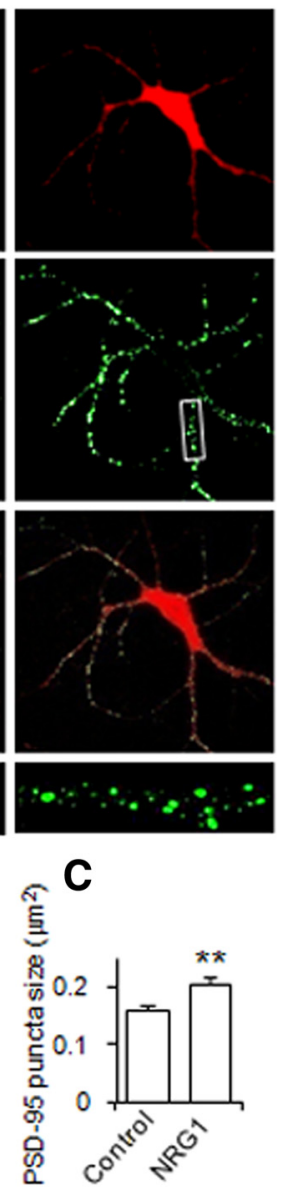

D
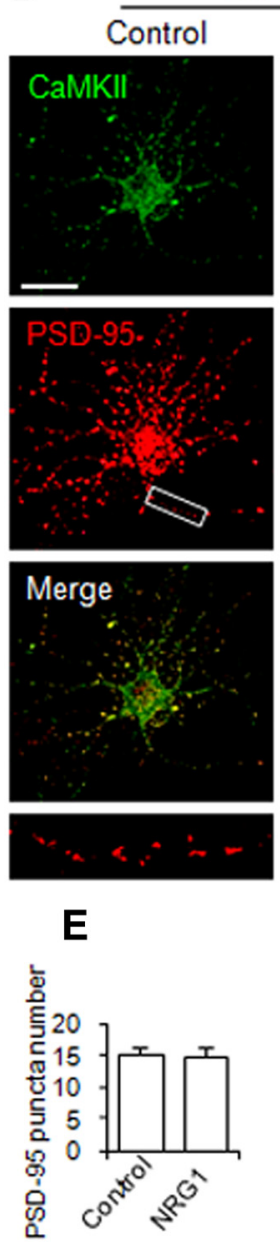

DIV $12+2$ NRG1
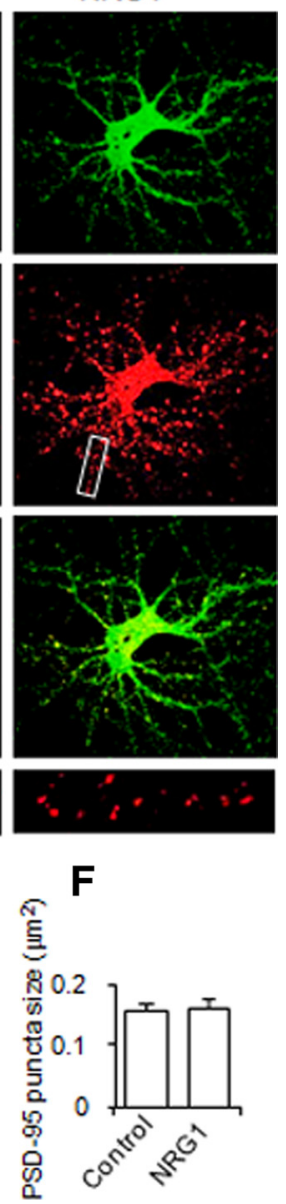

Figure 4. NRG1 induces excitatory synapse development in GABAergic but not glutamatergic neurons in hippocampus. NRG1 at 5 nm was applied to the low-density DIV12 dissociated hippocampal neurons for $2 \mathrm{~d}$. GABA, CaMKII, and PSD-95 were stained to represent GABAergic interneurons, glutamatergic neurons, and excitatory synapses, respectively. PSD-95 staining on GABApositive or CaMKII-positive neurons without or with NRG1 treatment is shown in $\boldsymbol{A}$ and $\boldsymbol{D}$, respectively. Scale bar, $30 \mu \mathrm{m}$; boxed area was enlarged in the respective bottom image. $\boldsymbol{B}, \boldsymbol{C}, \boldsymbol{E}, \boldsymbol{F}$, PSD-95 puncta, scored as Figure 1. Data shown are the mean \pm SEM of three individual experiments. ${ }^{* *} p<0.01$. For GABA-positive neurons ( $n=80$ and 78 for control and treated groups, respectively), puncta numbers are $17.3 \pm 1.0$ in the absence of NRG1 and $21.4 \pm 1.03$ in the presence of NRG1; size is $15.8 \pm 0.9$ in the absence of NRG1 and $20.5 \pm 1.2$ in the presence of NRG1. For CaMKII-positive neurons ( $n=82$ and 89 for control and treated groups, respectively), puncta numbers are $15.2 \pm 1.1$ in the absence of NRG1 and $14.8 \pm 1.3$ in the presence of NRG1; size is $15.8 \pm 1.0$ in the absence of NRG1 and $16.2 \pm 1.6$ in the presence of NRG1.

www.jneurosci.org as supplemental material). Noticeably, ectoErbB4 treatment reduced the number and size of PSD-95 puncta by $24 \pm 5 \%$ and $38 \pm 4 \%$, respectively (Fig. 2). These observations demonstrate a role of endogenous NRG1 in excitatory synapse formation in GABAergic interneurons.

NRG1 is expressed in the CNS and ErbB4 is present in both glutamatergic and GABAergic neurons (Yau et al., 2003), although recent studies suggested that ErbB4 may be exclusively expressed in interneurons (Abe et al., 2009; Vullhorst et al., 2009). To determine whether NRG1 was able to regulate the formation of excitatory synapses in glutamatergic neurons, DIV12 cortical neurons were stimulated without or with NRG1 for $2 \mathrm{~d}$ and stained for PSD-95 and CaMKII, a well-established marker for glutamatergic neurons (McDonald et al., 2002; Yau et al., 2003; Muller et al., 2006; Hu et al., 2010). NRG1 (5 nM) treatment did not seem to alter the number and size of PSD-95 puncta in GABA-negative or CaMKII-positive neurons (Fig. 3). This result could suggest that NRG1 has no significant effect on excitatory agreement with above morphological stud-

ies, indicated that NRG1 promotes formation of excitatory synapses on GABAergic interneurons, but not in pyramidal neurons.

\section{NRG1 increases the level and stability of PSD-95}

To investigate mechanisms by which NRG1 promotes excitatory synapse formation and maturation, we examined the levels of PSD-95, a postsynaptic protein critical in excitatory synapse development. Western blot analysis revealed that PSD-95 was increased in NRG1-treated neurons in comparison with control (by $46 \pm 18 \%$ and $41 \pm 18 \%$ for DIV $3+2$ and DIV $10+2$, respectively) (Fig. 6A,B). The levels of synapsin, a presynaptic marker, were increased (by $27 \pm 5 \%$ ) in DIV $3+2$ but not DIV $10+$ 2 neurons, in agreement with the notion that NRG1 increases the number of excitatory synapses in young, but not aged, neurons (Fig. 1D). However, NRG1 had no effect on protein levels or puncta number and size of gephyrin (Figs. $6 A, B$; supplemental Fig. S3, available at www.jneurosci.org as supplemental material), a protein enriched in postsynaptic membranes of inhibitory 
synapses, demonstrating the specific effect of NRG1 in promoting excitatory synapse development. Notice that highdensity culture was used for Western blot analysis here, whereas low-density culture was used for immunohistochemical study (Fig. 1). For reasons unknown, neurons appear to mature faster when cultured at high density (Parnas and Linial, 1997). Therefore, the data in Figures $1 D$ and $6 B$ are in general agreement that NRG1 promotes synapse formation at a younger age (with increased puncta number) and maturation at a late stage (with increased puncta size) (Figs. 1E, F, 6B).

The increase in PSD-95 protein level could suggest that NRG1 may regulate the stability of the protein. To test this hypothesis, DIV12 cortical neurons were pretreated with cycloheximide (CHX), a protein synthesis blocker, for $30 \mathrm{~min}$ before application of NRG1 for 12 or $24 \mathrm{~h}$. In control experiments, levels of PSD-95, gephyrin, and synapsin were all degraded in CHX-treated neurons (Fig. 6C). Remarkably, PSD-95 became more stable in NRG1-treated neurons as $71 \pm 4 \%$ of PSD-95 remained in NRG1-treated neurons, in contrast to $58 \pm 3 \%$ in control after $24 \mathrm{~h}$ of protein synthesis inhibition (Fig. 6C,D). This effect appeared to be specific because degradation of gephyrin and synapsin was apparently not altered by NRG1. To demonstrate that the effect of CHX was reversible by NRG1, DIV20 cortical neurons were pretreated with CHX for $30 \mathrm{~min}$ before cotreatment of NRG1 for 24 h. As shown in Figure 7, PSD-95 puncta size increased by $35 \pm 7 \%$ in the presence of NRG1, demonstrating the reversing effect. These results suggest that NRG1 could increase the stability of PSD-95, providing a mechanism by which NRG1 increases the number and size of PSD-95 puncta (Fig. 1).

\section{NRG1-mediated PSD-95 stabilization requires ErbB4 kinase activity}

Because ErbB4 is enriched in GABAergic interneurons, we determined whether it is necessary for NRG1 regulation of PSD-95 stability. High-density DIV14 neurons were treated with CHX

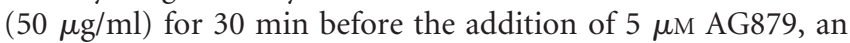
inhibitor of ErbB kinases (Woo et al., 2007; Liu et al., 2007). Levels of PSD-95, synapsin, and $\beta$-actin were analyzed by Western blotting. As shown in Figure 8, $A$ and $B$, PSD-95 protein degradation was dramatically increased in the presence of AG879. PSD- 95 was $27 \pm 7 \%$ of control $4 \mathrm{~h}$ after the addition of AG879. To determine whether that this effect occurred in GABAergic dendrites, low-density DIV21 neurons were pretreated with CHX before application of AG879 at indicated times. Neurons were fixed and stained for GABA and PSD-95 afterward. Both the number and size of PSD-95 puncta were reduced in a time-dependent manner (Fig. 8C-F). Four hours after AG879
A

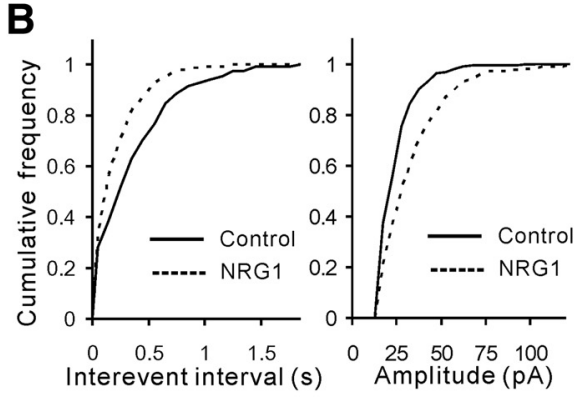

Control
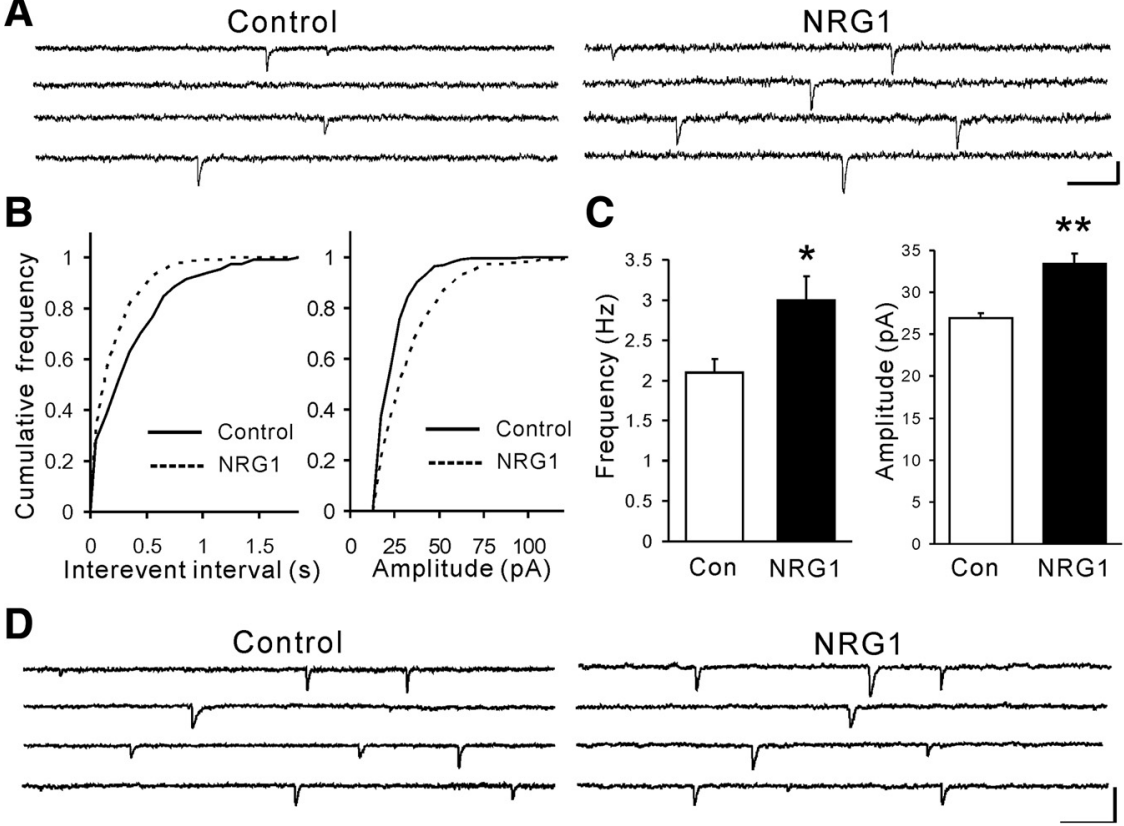

$\mathbf{F}$
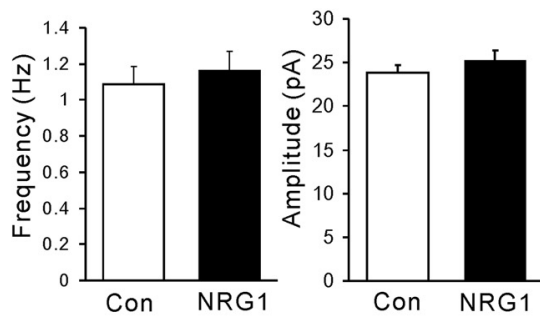

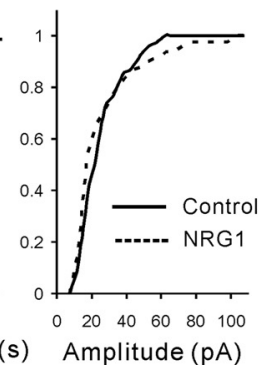

Figure 5. Both amplitude and frequency of $m E P S C s$ are enhanced in GABAergic interneurons, but not pyramidal neurons. E18 4 cells; NRG1, $3.00 \pm 0.29 \mathrm{~Hz}, 33.4 \pm 1.18 \mathrm{pA}, n=15$ cells; $\left.{ }^{*} p<0.05 ;{ }^{* *} p<0.01\right)$. D. Representative traces of mEPS(s from control and one NRG1-treated pyramidal neuron in whole-cell configuration. Calibration: 40 pA, 200 ms. $E$, Cumulative Smirnov test; $p>0.05$ ). $\boldsymbol{F}$, Histogram summary of data (mean \pm SEM; control $1.09 \pm 0.10 \mathrm{~Hz}, 23.9 \pm 0.83 \mathrm{pA}, n=15$ cells; $\mathrm{NRG1}, 1.16 \pm 0.11 \mathrm{~Hz}, 25.3 \pm 1.18 \mathrm{pA}, n=14$ cells; $p>0.05)$.

treatment, the number reduced by $40 \pm 6 \%$, and the size reduced by $46 \pm 8 \%$. These results suggested that the tyrosine kinase activity of ErbB4 is critical for PSD-95 stability in GABAergic interneurons. It is worth pointing out that AG879 could inhibit other tyrosine kinases. As shown in supplemental Figs. S4 and S5 (available at www.jneurosci.org as supplemental material), AG879 treatment could reduce gephyrin puncta in GABAergic neurons (supplemental Fig. S4, available at www.jneurosci.org as supplemental material) and PSD-95 puncta in glutamatergic neurons (supplemental Fig. S5, available at www.jneurosci.org as supplemental material). These data suggested that AG879 may have an off-target effect (see Discussion for details).

To address this question and to further determine the role of ErbB4 in PSD-95 stabilization, HEK293 cells were coexpressed with ErbB4 and PSD-95 cDNAs. HEK293 cells were used because the heterologous expression system allow for high expression of exogenous proteins, enabling biochemical characterization. HEK293 cells apparently contain necessary signaling components and have proved a valuable model to study NRG1 function 
A

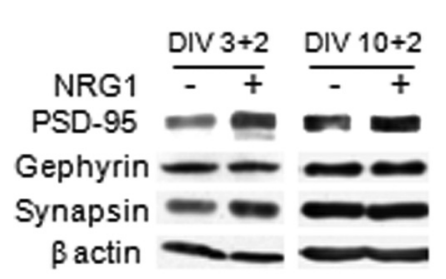

C

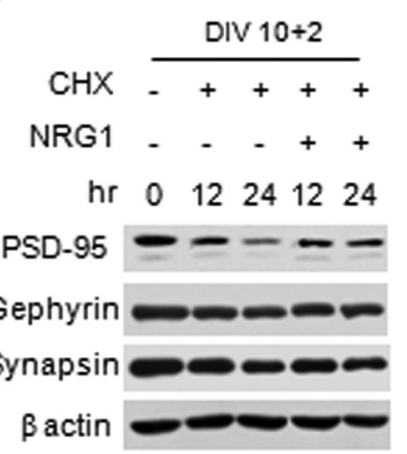

B

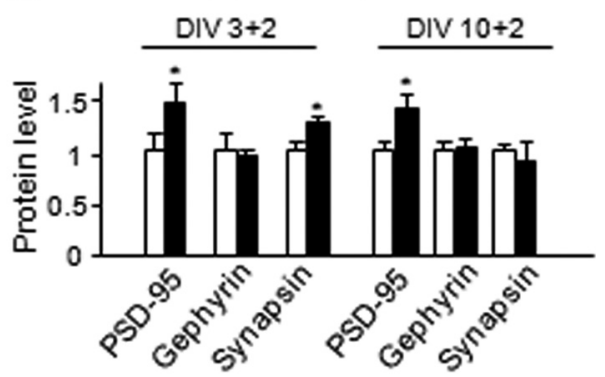

D

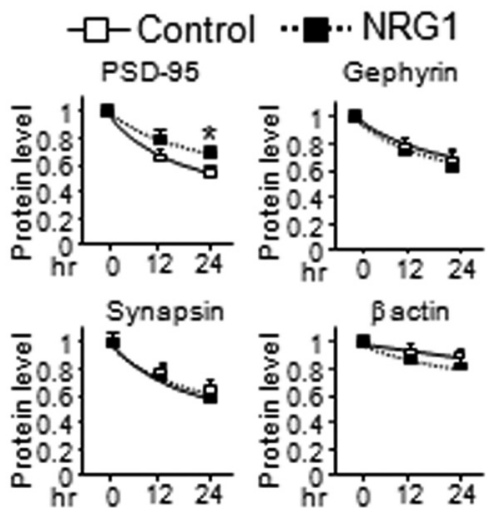

Figure 6. NRG1 increases the level and stability of PSD-95 protein. NRG1 at 5 nm was applied to DIV3 and DIV10 high-density dissociated cortical neurons for $2 \mathrm{~d}$. Cell lysate was collected and subjected to Western blot analysis. A, A representative blot of PSD-95, gephyrin, and synapsin. $\beta$ actin was included as loading control. $B$, Quantitative analysis (mean \pm SEM; $n=5$ and 4 for DIV3 +2 and DIV10 +2 , respectively). CHX ( $50 \mu \mathrm{g} / \mathrm{ml})$ was added to the high-density dissociated cortical neurons for $30 \mathrm{~min}$ before application of NRG1 for 12 and $24 \mathrm{~h}$. Cell lysate was collected and subjected to Western blot analysis. $C$, Representative blots of PSD-95, gephyrin, synapsin, and $\beta$-actin. $\boldsymbol{D}$, Quantitative analysis (mean $\pm \mathrm{SEM} ; n=4$ ). ${ }^{*} p<0.05$.

and signaling mechanisms (Yang et al., 2005). Two days after transfection, cells were treated with CHX for indicated times, and cell lysate was collected and analyzed for PSD-95 protein level. As shown in Figure 9, $A$ and $B$, expression of wild-type ErbB4, which leads to autoactivation (Yang et al., 2005), increased the stability of PSD-95. In control cells expressing the empty parental vector of ErbB 4 construct, $50 \pm 10 \%$ and $29 \pm 6 \%$ of PSD-95 protein remained at 12 and $24 \mathrm{~h}$, respectively, after inhibiting protein synthesis. The levels were increased to $73 \pm 5 \%$ and $59 \pm 4 \%$, respectively, in cells coexpressing wild-type ErbB4 (Fig. 9A,B). This effect was not observed in cells coexpressing kinase-dead ErbB4, suggesting that PSD-95 stability is enhanced by the tyrosine kinase activity of ErbB4. This notion is further supported by experiments that NRG1 treatment further increased PSD-95 levels in cells coexpressing with wild-type, but not kinase-dead, ErbB4 (Fig. 9C,D). To study whether the effect of ErbB4 on PSD-95 stability is specific, we coexpressed GFP cDNA with wildtype or kinase-dead ErbB4 cDNAs into HEK293 cells and detected GFP protein degradation afterward. GFP protein degradation rate remained unaltered in either wild-type or kinase-dead ErbB4 transfected cells (Fig. 9A,B). Moreover, NRG1 treatment had no effect on GFP protein level in either wild-type or kinasedead ErbB4 transfected cells (Fig. 9C,D). These results indicate that ErbB4 is sufficient to enhance PSD-95 stability in a manner dependent on its kinase activity.

In vivo evidence for a role of ErbB4 for postsynaptic differentiation of excitatory synapses in GABAergic interneurons

The above in vitro studies suggest a role of NRG1, via activating ErbB4, in excitatory synapse formation and maturation in
GABAergic interneurons. To test this hypothesis in vivo, we sought to specifically ablate ErbB4 in PV-positive interneurons where ErbB4 is enriched (Yau et al., 2003; Neddens and Buonanno, 2009). PV is a calcium-binding protein that is expressed in two types of interneurons, wide arbor and chandelier cells, which form perisomatic synapses onto pyramidal neurons (Markram et al., 2004). In rodent, PVpositive interneurons seem to predominate in the neocortex (Hof et al., 1999; Markram et al. 2004). Therefore, we generated $\mathrm{PV}$-Cre;ErbB $4^{-/-}$mice where ErbB4 was specifically ablated in PVpositive interneurons. To assist electrophysiological recording of GABAergic interneurons, the conditional mutant mice were further crossed with GAD67$\mathrm{GFP}^{+/-}$mice (Tamamaki et al., 2003).

The following two methods were used to identify PV-positive neurons. First, $\mathrm{PV}$-positive neurons are fast firing after injected with depolarizing $(+300 \mathrm{pA})$ somatic currents (supplemental Fig. S6, available at www.jneurosci.org as supplemental material), and their spikes are characteristically short in duration and without significant adaption (Markram et al. 2004) (supplemental Fig. S6, available at www.jneurosci.org as supplemental material). Second, recorded GFP-labeled cells were injected with biocytin and confirmed by subsequent costaining with PV antibody (data not shown). As shown in supplemental Fig. S6 (available at www. jneurosci.org as supplemental material), the resting membrane potential and $R_{\text {in }}$ of PV-positive interneurons in PFC layers II-V

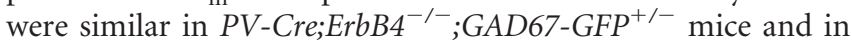
wild-type controls. These results indicated that specific ablation of ErbB4 in PV-positive interneurons may not change their intrinsic property.

Next, we recorded mEPSCs in PV-positive interneurons of ErbB4 mutant mice. As shown in Figure 10, their frequency was reduced in prefrontal cortical slices of the mutant mice compared with those of control mice, suggesting compromised excitatory synapses onto PV-positive interneurons. Moreover, the amplitude of mEPSCs was also decreased in the mutant mice (Fig. 10), indicating decreased density and response of postsynaptic receptors of glutamate in $\mathrm{PV}$-Cre;ErbB4 $4^{-/-}$mice. These results provided in vivo evidence for a critical role of ErbB4 in the assembly and possibly function of excitatory synapses in GABAergic interneurons, in agreement with above in vitro studies.

\section{Discussion}

Major findings of this paper are as follows. First, treatment with NRG1 increases the number of excitatory synapses in GABAergic interneurons (Fig. $1 A-D$ ), suggesting that NRG1 stimulates the formation of new synapses. This effect only occurs in developing, but not mature, neurons. Second, NRG1 increased the size of excitatory synapses in GABAergic interneurons (Fig. $1 A-C, E$ ), suggesting that NRG1 also strengthens existing synapses. In agreement with the morphological studies, NRG1 increased the frequency and amplitude of mEPSCs in GABAergic interneurons 
(Fig. 5). Third, ecto-ErbB4 treatment diminished both the number and size of excitatory synapses, suggesting the involvement of endogenous NRG1 (Fig. 2). Fourth, however, NRG1 treatment has no significant effect on either the number or size of excitatory synapses in glutamatergic neurons (Figs. 3, 4), suggesting its synaptogenic effect is specific to GABAergic interneurons. Fifth, NRG1 increases the stability of PSD-95 protein in the manner that requires tyrosine kinase activity of ErbB4 (Figs. 6-9). Finally, deletion of ErbB4 in PV-interneurons leads to reduced amplitude and frequency of mEPSCs (Fig. 10), providing in vivo evidence that ErbB4 is important in excitatory synapse formation or function in interneurons. Together, our findings suggest a novel synaptogenic role of NRG1 in excitatory synapse development, possibly via stabilizing PSD-95, and this effect is specific to GABAergic interneurons. While this paper was in revision, similar results were reported by Fazzari et al. (2010). In light of the association of the genes of both NRG1 and ErbB4 with schizophrenia and dysfunction of GABAergic system in this disorder, these results provide insight into its potential pathological mechanism.

Our data reveal two synaptogenic roles of NRG1/ErbB4 signaling in excitatory synapse development in GABAergic interneurons. It induces the formation of new synapse and, at the same time, facilitates synapse maturation. PSD-95 is a major scaffolding protein located at excitatory synapses (Cohen-Cory, 2002; Levinson and El-Husseini, 2005; McAllister, 2007; Keith and El-Husseini, 2008). It interacts with many important synaptic molecules such as NMDA receptor (Kornau et al., 1995), and it could enhance AMPA receptor trafficking, insertion, and retention at synapses (El-Husseini et al., 2000b; Chen et al., 2000, 2003; Dakoji et al., 2003; Schnell et al., 2002). In addition, PSD-95 has been implicated in synapse maturation (El-Husseini et al., 2000; Keith and El-Husseini, 2008). Despite the critical role of PSD-95 in CNS synapse development, little is known about how it becomes concentrated at the synapse. Previous studies showed that PSD-95 protein could be degraded by the E3 ligase Mdm2 via the proteasome pathway (Colledge et al., 2003). We showed here that the stability of PSD-95 is enhanced by NRG1, providing an intriguing mechanism for the NRG1 effect on synapse formation. We do not know at the moment exactly how NRG1 promotes PSD-95 stability. However, we showed that the NRG1 effect requires the kinase activity of ErbB4 because AG879, an inhibitor of ErbB kinases (Fukazawa et al., 2003), reduced PSD-95 puncta in the presence of CHX (Fig. 9). These results suggest for the first time the possible involvement of tyrosine phosphorylation in PSD-95 protein stability. It is worth pointing out that AG879 could inhibit other tyrosine kinases. Indeed, it reduced gephyrin puncta in GABAergic neurons and PSD-95 puncta in glutamatergic neurons where ErbB4 expression was low (supplemental Figs. S4, S5, available at www. jneurosci.org as supplemental material), suggesting that AG879 may have off-target effect. However, coexpression of ErbB4, but not its kinase-inactive mutant, increases PSD-95 stability (Fig. 9), in support of a role of ErbB4. Moreover, the involvement of

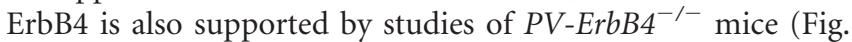
10). Future studies are necessary to investigate underlying molecular mechanisms.

Neuronal excitability relies on the summation of excitatory and inhibitory signals, which is in turn regulated by the number of excitatory and inhibitory synaptic contacts a neuron receive (Keith and El-Husseini, 2008). Therefore, the promoting effect of NRG1 on excitatory synapses could be critical to the function of GABAergic interneurons. We speculate that the loss of NRG1/ ErbB4 signaling may lead to reduced number of excitatory synapses of GABAergic interneurons. In line with this notion, mEPSC amplitudes and frequency were reduced in PVinterneurons of $\mathrm{PV}$-Cre; $\mathrm{ErbB} 4^{-/-}$mice. Consistently, GABA release from $\mathrm{PV}$-positive interneurons was reduced in $\mathrm{PV}$-Cre; $E r b B 4^{-1-}$ mice, and the mutant mice show behavioral deficits (Wen et al., 2010). These results, together with ours, indicate a novel function of NRG1 in the formation and maintenance of excitatory synapses in GABAergic neurons, presumably by stabilizing synaptic PSD-95.

\section{References}

Abe Y, Namba H, Zheng Y, Nawa H (2009) In situ hybridization reveals developmental regulation of ErbB1-4 mRNA expression in mouse midbrain: Implication of ErbB receptors for dopaminergic neurons. Neuroscience 161:95-110.

Anton ES, Ghashghaei HT, Weber JL, McCann C, Fischer TM, Cheung ID, 
A

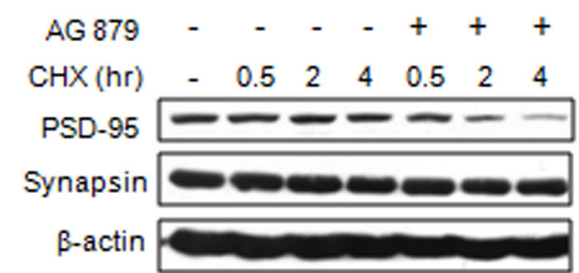

B

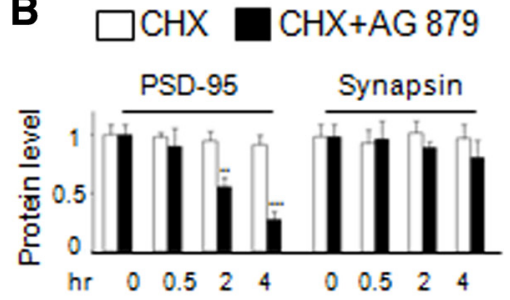

C
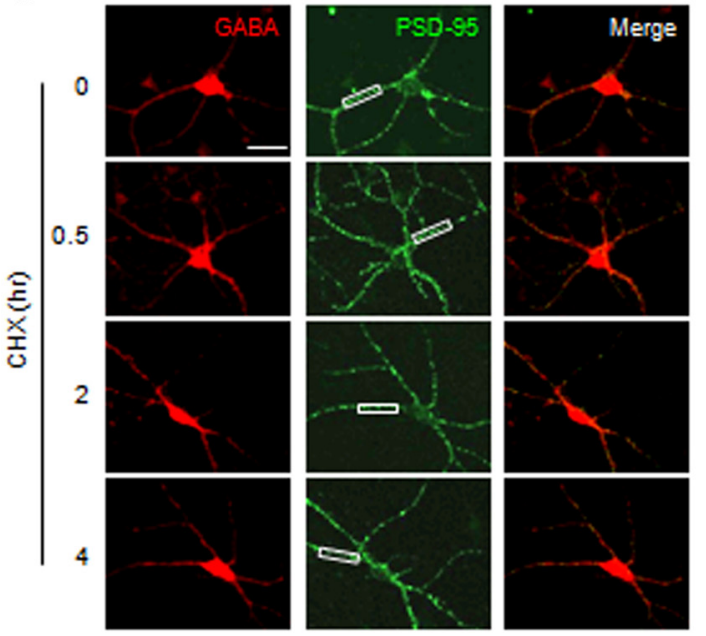

D
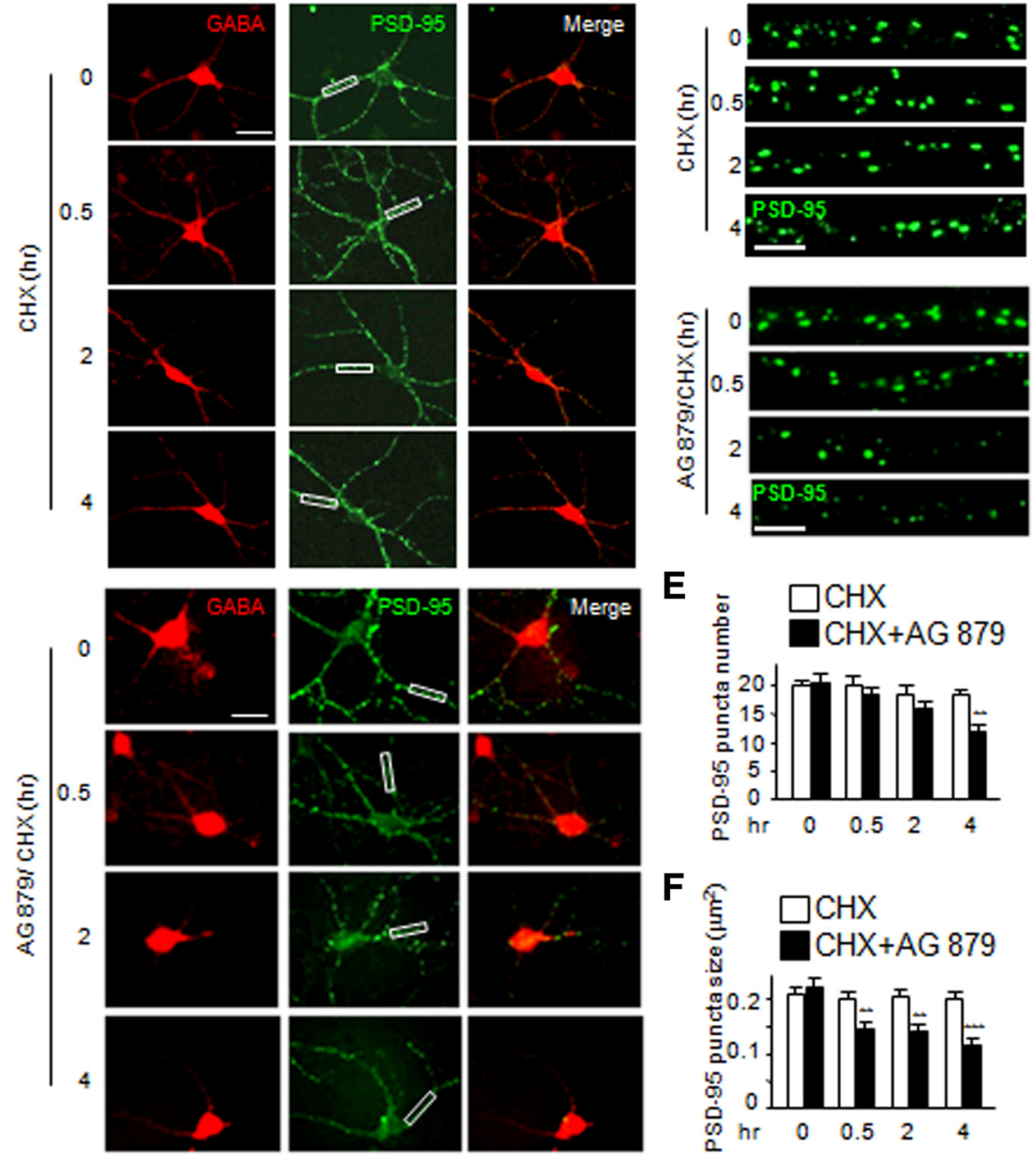

E

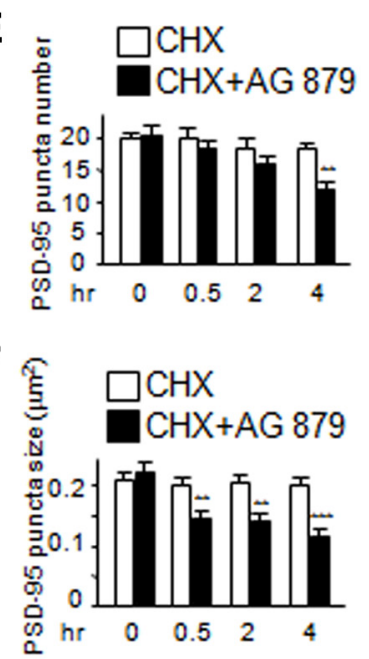

Figure 8. PSD-95 protein stability requires tyrosine kinase activity. High-density cortical neurons (DIV14) were pretreated with CHX (50 $\mu \mathrm{g} / \mathrm{ml})$ for $30 \mathrm{~min}$ before application of AG879 $(5 \mu \mathrm{m})$ for $0.5,2$, and $4 \mathrm{~h}$. Cell lysate was collected and subjected to Western blot analysis. $\boldsymbol{A}, \boldsymbol{B}$, A representative blot of PSD-95, synapsin, and $\beta$-actin $(\boldsymbol{A})$ and quantitative analysis ( $\boldsymbol{B}$; mean \pm SEM of 3 individual experiments). C, DIV21 low-density cortical neurons were pretreated with cycloheximide $(50 \mu \mathrm{g} / \mathrm{mll})$ for $30 \mathrm{~min}$ before application of AG879 $(1 \mu \mathrm{m})$ for $0.5,2$, and $4 \mathrm{~h}$. GABA and PSD-95 were stained. Boxed areas were enlarged in D.E, F, PSD-95 puncta number and size are scored as in Figure 1. Scale bars: $\boldsymbol{C}, 30 \mu \mathrm{m} ; \boldsymbol{D}, 5 \mu \mathrm{m}$. Data shown are the mean \pm SEM of three individual experiments. ${ }^{* *} p<0.01 ;{ }^{* * *} p<0.001$. For indicated times, puncta numbers of CHX only are 20.4 $\pm 1.0,20.1 \pm 1.1,18.0 \pm 0.88$, and 18.1 \pm 0.95 ; sizes are 22.0 $\pm 1.1,20.4 \pm 0.73$, $21.0 \pm 1.1$, and $20.3 \pm 0.94$, respectively $(n=56,56,58$, and 51 for $0,0.5,2$, and $4 \mathrm{~h}$, respectively). For CHX and AG879 cotreatment, puncta numbers are $20.8 \pm 1.9,18.2 \pm 1.3,15.5 \pm 1.1$, and $12.6 \pm 1.0$, and sizes are $22.4 \pm 2.0,14.2 \pm 1.7,13.8 \pm 1.3$, and $11.0 \pm$ 1.4 , respectively ( $n=55,64,63$, and 52 for $0,0.5,2$, and 4 h, respectively).

Gassmann M, Messing A, Klein R, Schwab MH, Lloyd KC, Lai C (2004) Receptor tyrosine kinase ErbB4 modulates neuroblast migration and placement in the adult forebrain. Nat Neurosci 7:1319-1328.

Arber S, Ladle DR, Lin JH, Frank E, Jessell TM (2000) ETS gene Er81 controls the formation of functional connections between group Ia sensory afferents and motor neurons. Cell 101:485-498.

Benes FM, Berretta S (2001) GABAergic interneurons: Implications for understanding schizophrenia and bipolar disorder. Neuropsychopharmacology 25:1-27.
Chen L, Chetkovich DM, Petralia RS, Sweeney NT, Kawasaki Y, Wenthold RJ, Bredt DS, Nicoll RA (2000) Stargazin regulates synaptic targeting of AMPA receptors by two distinct mechanisms. Nature 408:936-943.

Chen L, El-Husseini A, Tomita S, Bredt DS, Nicoll RA (2003) Stargazin differentially controls the trafficking of alpha-amino-3hydroxyl-5-methyl-4-isoxazolepropionate and kainate receptors. Mol Pharmacol 64: 703-706.

Cohen-Cory S (2002) The developing synapse: construction and modulation of synaptic structures and circuits. Science 298:770-776.

Colledge M, Snyder EM, Crozier RA, Soderling JA, Jin Y, Langeberg LK, Lu H, Bear MF, Scott JD (2003) Ubiquitination regulates PSD-95 degradation and AMPA receptor surface expression. Neuron 40:595-607.

Dakoji S, Tomita S, Karimzadegan S, Nicoll RA, Bredt DS (2003) Interaction of transmembrane AMPA receptor regulatory proteins with multiple membrane associated guanylate kinases. Neuropharmacology 45:849-856.

El-Husseini AE, Schnell E, Chetkovich DM, Nicoll RA, Bredt DS (2000) PSD-95 involvement in maturation of excitatory synapses. Science 290:1364-1368.

El-Husseini AE, Topinka JR, Lehrer-Graiwer JE, Firestein BL, Craven SE, Aoki C, Bredt DS (2000b) Ion channel clustering by membraneassociated guanylate kinases. Differential regulation by $\mathrm{N}$-terminal lipid and metal binding motifs. J Biol Chem 275:23904-23910.

Fazzari P, Paternain AV, Valiente M, Pla R, Luján R, Lloyd K, Lerma J, Marín O, Rico B (2010) Control of cortical GABA circuitry development by Nrg1 and ErbB4 signalling. Nature 464:1376-1380.

Flames N, Long JE, Garratt AN, Fischer TM, Gassmann M, Birchmeier C, Lai C, Rubenstein JL, Marin O (2004) Short- and long-range attraction of cortical GABAergic interneurons by neuregulin-1. Neuron 44:251-261.

Fukazawa R, Miller TA, Kuramochi Y, Frantz S, Kim YD, Marchionni MA, Kelly RA, Sawyer DB (2003) Neuregulin 1 protects ventricular myocytes from anthracycline-induced apoptosis via erbB4-dependent activation of PI3-kinase/Akt. J Mol Cell Cardiol 35:1473-1479.

Garcia-Rivello H, Taranda J, Said M, CabezaMeckert P, Vila-Petroff M, Scaglione J, Ghio S, Chen J, Lai C, Laguens RP, Lloyd KC, Hertig CM (2005) Dilated cardiomyopathy in erbb4-deficient ventricular muscle. Am J Physiol Heart Circ Physiol 289:H1153-H1160.

Heinke B, Ruscheweyh R, Forsthuber L, Wunderbaldinger G, Sandkuhler J (2004) Physiological, neurochemical and morphological properties of a subgroup of GABAergic spinal lamina II neurones identified by expression of green fluorescent protein in mice. J Physiol

560:249-266.

Hippenmeyer S, Vrieseling E, Sigrist M, Portmann T, Laengle C, Ladle DR, Arber S (2005) A developmental switch in the response of DRG neurons to ETS transcription factor signaling. PLoS Biol 3:e159.

Hof PR, Glezer II, Conde F, Flagg RA, Rubin MB, Nimchinsky EA, Vogt Weisenhorn DM (1999) Cellular distribution of the calcium-binding proteins parvalbumin, calbindin, and calretinin in the neocortex of mammals: phylogenetic and developmental patterns. J Chem Neuroanat 16:77-116. 
Hu JL, Liu G, Li YC, Gao WJ, Huang YQ (2010) Dopamine D1 receptor-mediated NMDA receptor insertion depends on Fyn but not Src kinase pathway in prefrontal cortical neurons. Mol Brain 3:20.

Huang YZ, Won S, Ali DW, Wang Q, Tanowitz M, Du QS, Pelkey KA, Yang DJ, Xiong WC, Salter MW, Mei L (2000) Regulation of neuregulin signaling by PSD-95 interacting with ErbB4 at CNS synapses. Neuron 26:443-455.

Keith D, El-Husseini A (2008) Excitation control: Balancing PSD-95 function at the synapse. Front Mol Neurosci 1:4.

Kornau HC, Schenker LT, Kennedy MB, Seeburg PH (1995) Domain interaction between NMDA receptor subunits and the postsynaptic density protein PSD-95. Science 269:1737-1740.

Krivosheya D, Tapia L, Levinson JN, Huang K, Kang Y, Hines R, Ting AK, Craig AM, Mei L, Bamji SX, El-Husseini A (2008) ErbB4-neuregulin signaling modulates synapse development and dendritic arborization through distinct mechanisms. J Biol Chem 283:32944-32956.

Lai C, Lemke G (1991) An extended family of protein-tyrosine kinase genes differentially expressed in the vertebrate nervous system. Neuron 6:691-704.

Law AJ, Lipska BK, Weickert CS, Hyde TM, Straub RE, Hashimoto R, Harrison PJ, Kleinman JE, Weinberger DR (2006) Neuregulin 1 transcripts are differentially expressed in schizophrenia and regulated by $5^{\prime}$ SNPs associated with the disease. Proc Natl Acad Sci U S A 103:6747-6752.

Law AJ, Kleinman JE, Weinberger DR, Weickert CS (2007) Disease-associated intronic variants in the ErbB4 gene are related to altered ErbB4 splice-variant expression in the brain in schizophrenia. Hum Mol Genet 16:129-141.

Letinic K, Zoncu R, Rakic P (2002) Origin of GABAergic neurons in the human neocortex. Nature 417:645-649.

Levinson JN, El-Husseini A (2005) New players tip the scales in the balance between excitatory and inhibitory synapses. Mol Pain 1:12.

Lewis DA, Levitt P (2002) Schizophrenia as a disorder of neurodevelopment. Annu Rev Neurosci 25:409-432.

Li B, Woo RS, Mei L, Malinow R (2007) The neuregulin-1 receptor erbB4 controls glutamatergic synapse maturation and plasticity. Neuron 54:583-597.

Liu Y, Tao YM, Woo RS, Xiong WC, Mei L (2007) Stimulated ErbB4 internalization is necessary for neuregulin signaling in neurons. Biochem Biophys Res Commun 354:505-510.

Lopez-Bendito G, Cautinat A, Sanchez JA, Bielle F, Flames N, Garratt AN, Talmage DA, Role LW, Charnay P, Marin O, Garel S (2006) Tangential neuronal migration controls axon guidance: A role for neuregulin-1 in thalamocortical axon navigation. Cell 125:127-142.

Markram $\mathrm{H}$, Toledo-Rodriguez $\mathrm{M}$, Wang $\mathrm{Y}$, Gupta A, Silberberg G, Wu C (2004) Interneurons of the neocortical inhibitory system. Nat Rev Neurosci 5:793-807.

McAllister AK (2007) Dynamic aspects of CNS synapse formation. Annu Rev Neurosci 30:425-450.

McDonald AJ, Muller JF, Mascagni F (2002) GABAergic innervation of alpha type II calcium/ calmodulin-dependent protein kinase immunore-
A

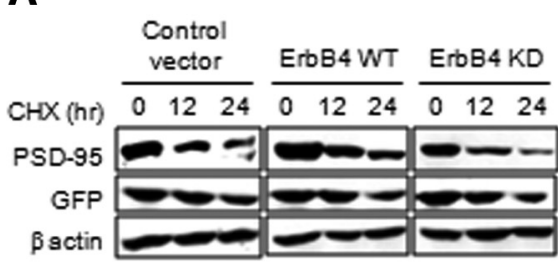

B

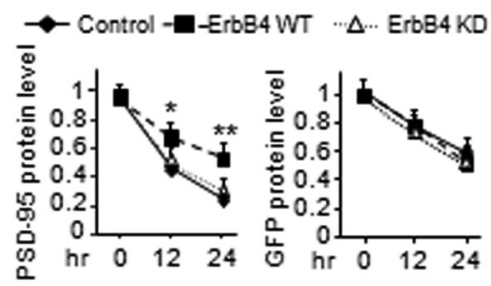

C

Contro

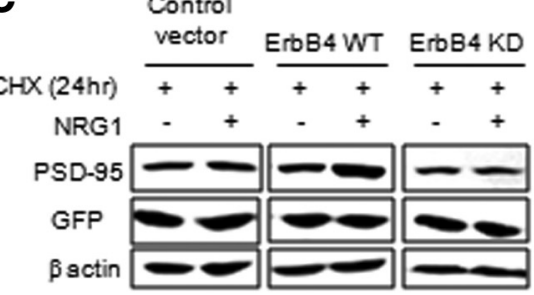

D

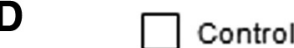

NRG1
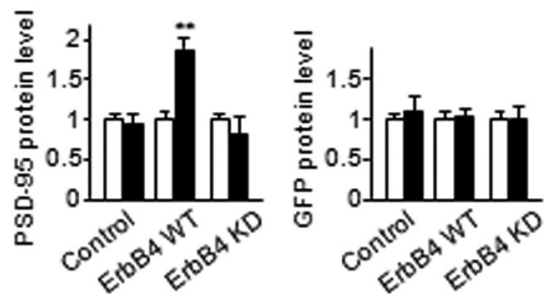

Figure 9. NRG1-induced PSD-95 stabilization requires kinase activity of ErbB4. $\boldsymbol{A}, \boldsymbol{B}$, Myc-tagged PSD-95 or GFP CDNA was coexpressed with either wild-type or kinase-dead ErbB4 CDNA or with the parental DNA construct of ErbB4 in HEK293 cells. CHX at $20 \mu \mathrm{g} / \mathrm{ml}$ was applied to the transfected cells for 12 or $24 \mathrm{~h}$ after $2 \mathrm{~d}$ transfection. $A$, Cell lysate was collected and analyzed by Western blotting. $\boldsymbol{B}$, Quantitative analysis. $\beta$ actin was served as an equal loading control. $\boldsymbol{C}$, Transfected cells were pretreated with $20 \mu \mathrm{g} / \mathrm{ml} \mathrm{CHX} \mathrm{for} 30$ min before cotreatment of NRG1 at $5 \mathrm{~nm}$ for $24 \mathrm{~h}$. Cell lysate was subjected to Western blotting. $\boldsymbol{D}$, Quantified data. Data are shown as the mean \pm SEM of six individual experiments. ${ }^{*} p<0.05$; ${ }^{* *} p<0.01$.
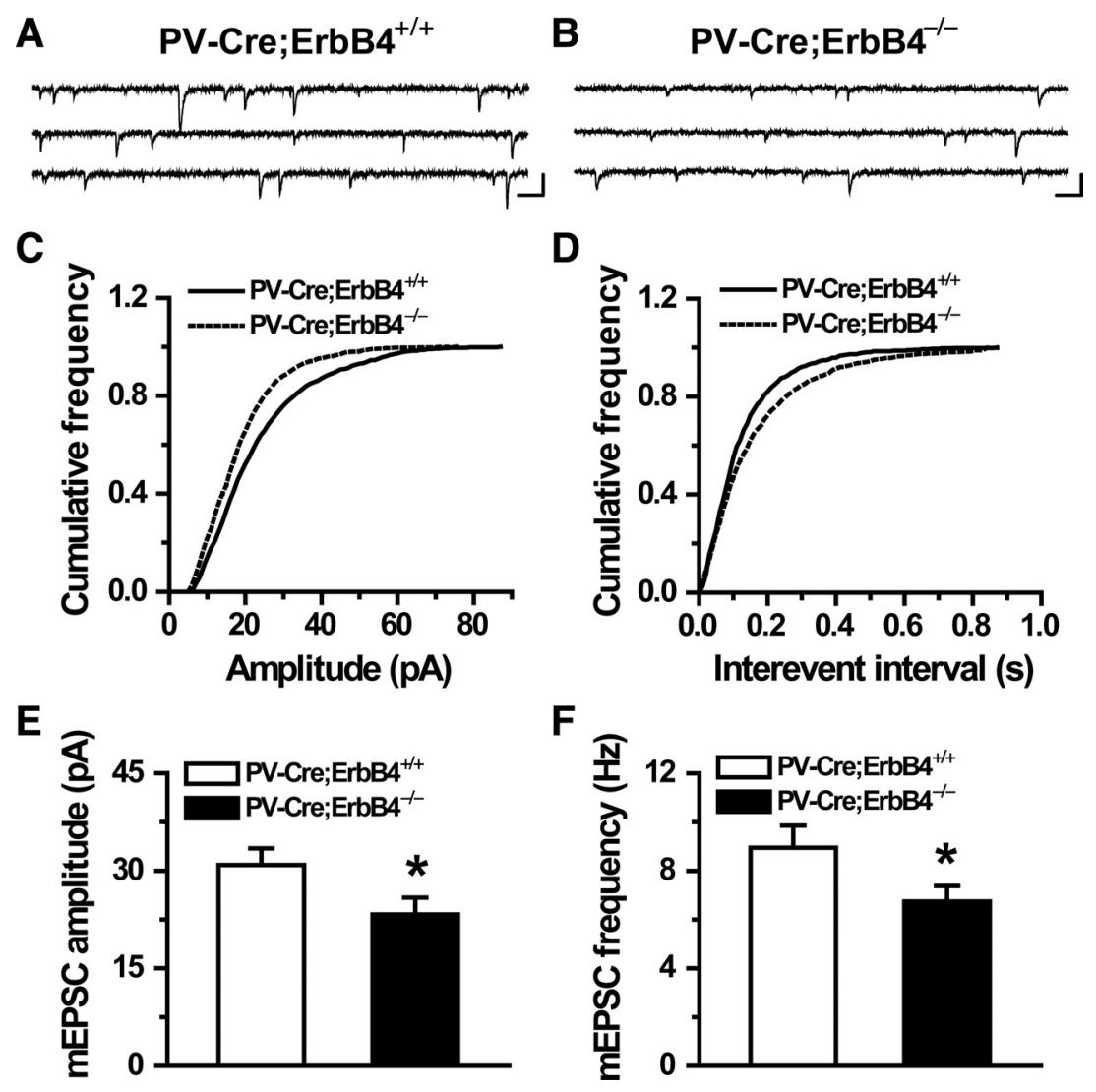

Figure 10. Conditional mutant mice lacking ErbB4 in PV-interneurons show deficits in excitatory synaptic activity. $A, B$, Representative traces of mEPSCs of one PV-positive interneuron in PV-Cre;ErbB4 ${ }^{+/+}(\boldsymbol{A})$ or in PV-Cre; ErbB4 ${ }^{-/-}(\boldsymbol{B}) \mathrm{PFC}$ slices. Calibration: $40 \mathrm{pA}, 50 \mathrm{~ms}$. C, Cumulative distribution for mEPSC amplitude of data in $\boldsymbol{A}$ and $\boldsymbol{B}$ (Kolmogorov-Smirnov test; $p<0.01$ ). $\boldsymbol{D}$, Cumulative distribution for mEPSC interevent intervals of data in $\boldsymbol{A}$ and $\boldsymbol{B}$ (Kolmogorov-Smirnov test; $p<0.01) . \boldsymbol{E}, \boldsymbol{F}$, Histogram summary of data (mean $\pm \mathrm{SEM} ;{ }^{*} p<0.05 ; n=22$ and 19 for ErbB4 ${ }^{-1-}$ mice and ErbB4 ${ }^{+1+}$ controls, respectively). 
active pyramidal neurons in the rat basolateral amygdala. J Comp Neurol 446:199-218.

Mei L, Xiong WC (2008) Neuregulin 1 in neural development, synaptic plasticity and schizophrenia. Nat Rev Neurosci 9:437-452.

Morabito MA, Sheng M, Tsai LH (2004) Cyclin-dependent kinase 5 phosphorylates the N-terminal domain of the postsynaptic density protein PSD-95 in neurons. J Neurosci 24:865-876.

Muller JF, Mascagni F, McDonald AJ (2006) Pyramidal cells of the rat basolateral amygdala: synaptology and innervation by parvalbuminimmunoreactive interneurons. J Comp Neurol 494:635-650.

Neddens J, Buonanno A (2009) Selective populations of hippocampal interneurons express ErbB4 and their number and distribution is altered in ErbB4 knockout mice. Hippocampus 20:724-744.

Parnas D, Linial M (1997) Acceleration of neuronal maturation of P19 cells by increasing culture density. Brain Res Dev Brain Res 101:115-124.

Roberts E (1972) Prospects for research on schizophrenia. an hypotheses suggesting that there is a defect in the GABA system in schizophrenia. Neurosci Res Program Bull 10:468-482.

Schnell E, Sizemore M, Karimzadegan S, Chen L, Bredt DS, Nicoll RA (2002) Direct interactions between PSD-95 and stargazin control synaptic AMPA receptor number. Proc Natl Acad Sci U S A 99:13902-13907.

Stefansson H, Sigurdsson E, Steinthorsdottir V, Bjornsdottir S, Sigmundsson T, Ghosh S, Brynjolfsson J, Gunnarsdottir S, Ivarsson O, Chou TT, Hjaltason O, Birgisdottir B, Jonsson H, Gudnadottir VG, Gudmundsdottir E, Bjornsson A, Ingvarsson B, Ingason A, Sigfusson S, Hardardottir H, et al. (2002) Neuregulin 1 and susceptibility to schizophrenia. Am J Hum Genet 71:877-892.
Tamamaki N, Yanagawa Y, Tomioka R, Miyazaki J, Obata K, Kaneko T (2003) Green fluorescent protein expression and colocalization with calretinin, parvalbumin, and somatostatin in the GAD67-GFP knock-in mouse. J Comp Neurol 467:60-79.

Vullhorst D, Neddens J, Karavanova I, Tricoire L, Petralia RS, McBain CJ, Buonanno A (2009) Selective expression of ErbB4 in interneurons, but not pyramidal cells, of the rodent hippocampus. J Neurosci 29:12255-12264.

Wen L, Lu YS, Zhu XH, Li XM, Woo RS, Chen YJ, Yin DM, Lai C, Terry AV, Vazdarjanova A, Xiong WC, Mei L (2010) Neuregulin 1 regulates pyramidal neuron activity via ErbB4 in parvalbumin-positive interneurons. Proc Natl Acad Sci U S A 107:1211-1216.

Woo RS, Li XM, Tao Y, Carpenter-Hyland E, Huang YZ, Weber J, Neiswender H, Dong XP, Wu J, Gassmann M, Lai C, Xiong WC, Gao TM, Mei L (2007) Neuregulin-1 enhances depolarization-induced GABA release. Neuron 54:599-610.

Yang JZ, Si TM, Ruan Y, Ling YS, Han YH, Wang XL, Zhou M, Zhang HY, Kong QM, Liu C, Zhang DR, Yu YQ, Liu SZ, Ju GZ, Shu L, Ma DL, Zhang D (2003) Association study of neuregulin 1 gene with schizophrenia. Mol Psychiatry 8:706-709.

Yang XL, Huang YZ, Xiong WC, Mei L (2005) Neuregulin-induced expression of the acetylcholine receptor requires endocytosis of ErbB receptors. Mol Cell Neurosci 28:335-346.

Yau HJ, Wang HF, Lai C, Liu FC (2003) Neural development of the neuregulin receptor ErbB4 in the cerebral cortex and the hippocampus: Preferential expression by interneurons tangentially migrating from the ganglionic eminences. Cereb Cortex 13:252-264. 